\title{
PLASMA BNP (B-TYPE NATRIURETIC PEPTIDE) AND HEART FAILURE: A CASE-CONTROL STUDY
}

\author{
PARVIN SULTANA ${ }^{1}$, MD. MOZAMMEL HOQUE ${ }^{2}$, SAMINA SHAFIULLAH ${ }^{3}$
}

\begin{abstract}
Background: Accurate diagnosis of heart failure $(\mathrm{HF})$ is essential for its proper management and logical drug therapy to reduce morbidity and mortality. In this perspective, researchers are in search of a good biomarker as complementary to the clinical parameters to improve the performance of HF diagnosis. B-type natriuretic peptide (BNP) secreted by cardiac ventricles in HF has emerged as a new promising biomarker in this regard.

Objective: Evaluation of plasma BNP concentration in HF cases.

Methods: In a hospital based case-control study, 100 HF cases and 80 age and sex matched control subjects without HF were enrolled by non random sampling. Plasma BNP was measured in all study subjects and then compared between cases and controls.

Results: Median plasma BNP concentration in HF $(446.5 \mathrm{pg} / \mathrm{ml}$, range $16.8-4000 \mathrm{pg} / \mathrm{ml})$ found to be significantly high compared to that in control subjects $(69.5 \mathrm{pg} / \mathrm{ml}$, range $0.6-627.5 \mathrm{pg} / \mathrm{ml})$.

Conclusion: In HF patients, plasma BNP is raised significantly. So it can be a promising biomarker for diagnosis of $\mathrm{HF}$.
\end{abstract}

Keyword: B-type natriuretic peptide, heart failure

\section{Introduction}

Heart failure is a common, highly morbid cardiovascular disorder associated with perturbations in cardiac structure and function culminating in the failure of heart to meet up the perfusion demand of peripheral tissues.

Incidence of heart failure is gradually increasing. It is nearly as common as diabetes in older adults, occurring in $2 \%$ of the adult population and rising to $3 \%$ in adults over 75 years age. About $35 \%$ of these patients hospitalize annually and 50\% die within 5 years. ${ }^{1}$

For individuals more than 40 years, the life time risk of developing heart failure has been estimated to about $20 \%$ for both sexes. The incidence of heart failure is highest in peoples older than 65 years. This segment of population is growing rapidly, ensuring an epidemic of heart failure that will continue to grow as the population ages. ${ }^{2}$ According to Boon et al. the prevalence of heart failure rises from around $1 \%$ in the age group $50-59$ years to about $5-10 \%$ among those aged $80-89$ years. ${ }^{3}$
The most common cause of heart failure is the ischemic heart disease. Due to the seminal improvement in diagnosis and treatment of patients with Acute Coronary Syndrome (ACS) in recent past, more patients are now surviving ACS than in previous decades and are left at risk for development of heart failure. ${ }^{4}$ Half of patients carrying a diagnosis of $\mathrm{HF}$ die within 4 years and in patients with severe HF more than $50 \%$ die within 1 year. ${ }^{5}$ So heart failure is a dreadful condition as far as prognosis is concerned. Good management of heart failure depends on early accurate etiological diagnosis partly because in some situation a specific remedy is available but mainly because a clear understanding of pathophysiology is essential to logical drug therapy. ${ }^{3}$

The classic symptoms of heart failure (e.g. fatigue, cough, dyspnea, orthopnea, pulmonary edema, peripheral edema) are non-specific and not sensitive enough to be used as a basis for accurate diagnosis since other diseases (e.g. COPD) can produce a similar clinical presentation. ${ }^{6}$ The two chief causes of dyspnea, congestive heart failure and lung disease

1. Assistant Professor, Dept. of Biochemistry, Shaheed Suhrawardi Medical College.

2. Professor, Dept. of Biochemistry, BSMMU.

3. Medical Officer, Dept. of Biochemistry, BSMMU.

Correspondence: Dr. Parvin Sultana, Assistant Professor, Dept. of Biochemistry, Shaheed Suhrawardi Medical College 
are often difficult to differentiate. ${ }^{7}$ As a result both under and over diagnosis of $\mathrm{HF}$ is common especially in elderly population, obese and patient with underlying lung disease. ${ }^{8}$ In a recent survey in cardiac emergency setting, doctors are found to be unsure of the diagnosis of $\mathrm{HF}$ in $40 \%$ of patients they encounter. ${ }^{9}$

Many aspects of heart failure still remain as clinical challenges. We not only have difficulty in diagnosing heart failure, we have difficulty in assessing the short term and long term results of treatment both in hospital and outpatient settings. ${ }^{6,10}$

Until now echocardiogram is regarded as the gold standard laboratory tool to diagnose heart failure inspite of its limitations. Echocardiogram is mostly concerned to characterize the specific structural and functional abnormalities associated with the syndrome but do not determine the diagnosis of heart failure. $^{2}$

Although echocardiogram can detect the systolic dysfunction, however 50\% patients presented with clinical heart failure have normal systolic function and $50 \%$ patients with echocardiographic systolic dysfunction found to have no symptoms of heart failure. Thus low ejection fraction is not synonymous with the diagnosis of heart failure. ${ }^{11}$

Echocardiogram as a conventional cardiac function test is time consuming, costly, not easily accessible especially in an emergency care setting, needs expertise interpretation and often do not correlate well with patients symptomatic scenario. Therefore, health personnel are searching for inexpensive, specific, sensitive, readily available and easily interpretable diagnostic aid to diagnose heart failure irrespective of underlying etiopathophysiology. Cardiac natriuretic hormones have been researched for such a diagnostic value. In this perspective, Btype natriuretic peptide (BNP) has come to light as an ideal biomarker with high diagnostic and prognostic weight for heart failure patients regardless of its type and causes.

B-type natriuretic peptide (BNP) is a cardiac neurohormone specially secreted from the cardiac ventricles in response to ventricular volume expansion, pressure overload and resultant increased wall tension. ${ }^{9}$

In heart failure, the persistent progressive cardiac congestion, elevation of left ventricular filling pressure generates mounting myocardial stress leading to increased BNP synthesis. Plasma BNP concentration increases in heart failure in proportion to its severity. ${ }^{4,12}$

To evaluate the utility of BNP assay, Dao et al. performed BNP measurement on 250 patients who came to the emergency room for shortness of breath and reviewed afterwards by cardiologists to determine appropriate diagnosis. ${ }^{13}$ Emergency doctors made an incorrect diagnosis in $12 \%$ of patients: half were diagnosed as $\mathrm{HF}$ but did not have it and $\mathrm{HF}$ was missed in the others. Of the 30 incorrect diagnoses, 29 would likely have been correct had BNP measurements been available.

BNP discriminates accurately between cardiac and noncardiac dyspnea, especially in the emergency setting with a high specificity, sensitivity and accuracy. ${ }^{14}$ Maisel and colleagues also demonstrated the value of plasma BNP to differentiate dyspnea due to congestive heart failure and other causes. ${ }^{4}$ They concluded that the value of plasma BNP in adjunct with other clinical parameters leads to diagnosis of congestive heart failure in acute care setting.

Prevalence of $\mathrm{HF}$ in our population is alarmingly increasing. Access to echocardiogram is very limited especially at primary and secondary level of our health care system, particularly in emergency care setting. So in our scenario plasma BNP can easily be exploited for diagnosis, clinical staging, risk assessment and risk stratification of heart failure. Plasma BNP measurement is relatively inexpensive, readily available and easily interpretable in comparison to echocardiogram. Therefore, measurement of plasma BNP hopefully will facilitate the rapid correct diagnosis of $\mathrm{HF}$ to reduce its morbidity and mortality in our population.

Large body of evidences is now in a consensus to float plasma BNP as a diagnostic and prognostic biomarker for heart failure patients. However, most of these findings are derived from white population. Works on Asians are relatively few and available data from Bangladesh on this issue is scarce. This study aimed to measure the plasma BNP in HF patients and to evaluate its association with heart failure. 


\section{Materials and Methods}

In this hospital based case control study 100 cases with $\mathrm{HF}$ and 80 age and sex matched controls without HF were selected on the basis of their clinical, ECG and echocardiographic findings from Bangabandhu Sheikh Mujib Medical University (BSMMU) hospital, Dhaka through convenient sampling during the period of January 2008 to December 2008. All study subjects were free from ischemic heart disease, renal failure, non cardiac fluid overload, thyroid disorders and liver diseases. Ethical clearance for the study was taken from the central ethical committee of BSMMU and informed written consent of all study subjects were taken prior to their enrollment. For all study subjects preformed questionnaire was used to collect data. Blood sample was collected aseptically and eventually plasma was used for measurement of BNP by microparticle enzyme immunoassay (MEIA) principle. ${ }^{15}$ Data were analyzed using SPSS (version 12.0). To find out statistical significance Mann-Whitney-U-test was done and $\mathrm{P}<0.05$ was considered as statistically significant.

\section{Results}

In this case control study 100 diagnosed HF cases (male-61, female-39) with mean age 41.1 years (age range 10-70 years) and 80 healthy control subjects (male-40, female-40) with mean age 36.9 years (age range 15-70 years) were enrolled (Table I). In HF cases median plasma BNP concentration found to be $446.5 \mathrm{pg} / \mathrm{ml}$ with the range of $16.8-4000 \mathrm{pg} / \mathrm{ml}$ and that in control subjects found to be $69.5 \mathrm{pg} / \mathrm{ml}$ with the range of $0.6-627.5 \mathrm{pg} / \mathrm{ml}$. Mann-Whitney-U-test shows plasma BNP concentration to be significantly high $(\mathrm{P}<0.001)$ in $\mathrm{HF}$ cases compared to that in control subjects (Table II).

Table I

Age and sex distribution of study subjects

\begin{tabular}{lccccc}
\hline Subject & $\begin{array}{c}\text { Total } \\
\text { number }\end{array}$ & $\begin{array}{c}\text { Mean } \\
\text { age (yr) }\end{array}$ & $\begin{array}{c}\text { Age } \\
\text { range }\end{array}$ & M & F \\
\hline $\begin{array}{l}\text { Cases } \\
\text { (with HF) }\end{array}$ & 100 & 41.1 & $10-70$ & 61 & 39 \\
$\begin{array}{l}\text { Control } \\
\text { (without HF) }\end{array}$ & 80 & 36.9 & $15-70$ & 40 & 40 \\
\hline
\end{tabular}

Table II

Comparison of plasma BNP between cases (HF) and control

\begin{tabular}{lccc}
\hline Subject & \multicolumn{2}{c}{$\begin{array}{c}\text { Plasma BNP } \\
(\mathrm{pg} / \mathrm{ml})\end{array}$} & $\begin{array}{c}\text { Level of } \\
\text { significant }(\mathrm{p} \text {-value })\end{array}$ \\
& Median & Range & \\
\hline Cases $(\mathrm{n}=100)$ & 446.5 & $16.8-4000$ & $\mathrm{P}<0.001$ \\
Control $(\mathrm{n}=80)$ & 69.5 & $0.6-627.5$ & \\
\hline
\end{tabular}

P-value reached by Mann-Whitney-U-test

\section{Discussion}

This study has revealed the median plasma BNP concentration in $\mathrm{HF}$ subjects to be $446.5 \mathrm{pg} / \mathrm{ml}$ and that in subjects without HF $69.5 \mathrm{pg} / \mathrm{ml}$. Statistical analysis showed that plasma BNP concentration is significantly raised in $\mathrm{HF}$ subjects compared to control subjects without HF. Our findings regarding plasma BNP concentration in HF found in agreement with that of other researchers. Cowei et al. found plasma BNP concentration in $\mathrm{HF}$ cases $(221.1 \mathrm{pg} / \mathrm{ml})$ significantly raised compared to non HF group $(48.0 \mathrm{pg} / \mathrm{ml}) .{ }^{16}$ Another study done by Dao et al. also similarly demonstrated the mean plasma BNP concentration in patients with HF to be significantly higher than that in patients without HF (1076 \pm $138 \mathrm{pg} / \mathrm{ml}$ vs $38 \pm 4 \mathrm{pg} / \mathrm{ml}) .{ }^{13}$ Rahman et al in his small case control study $(\mathrm{HF}$ case $=60$, control $=30)$ on Bangladeshi HF cases found median plasma BNP concentration in case and control $485.93 \mathrm{pg} / \mathrm{ml}$ and $70.17 \mathrm{pg} / \mathrm{ml}$ respectively. ${ }^{17} \mathrm{He}$ also showed plasma $\mathrm{BNP}$ concentration to be significantly higher in cases compared with that of control.

In failing hearts, remarkable changes occur to the heart and peripheral vascular system in response to the hemodynamic changes. These physiological changes are compensatory. However, with progression of heart failure these mechanisms are overwhelmed and become pathophysiological. ${ }^{18}$ The primary abnormality in HF is diminished ventricular function leading to diminished cardiac output which can lead to deleterious increase in both after load and preload.

In chronic ventricular dysfunction, due to sustained cardiac pressure and volume overload, BNP is regarded as more suitable marker than ANP (atrial natriuretic peptide) which are acutely responsive hormone. ${ }^{19}$ In cardiac volume and pressure overload, ANP gene expression is induced by increased preload of heart, whereas BNP primarily sensitive to 
increased after load. Thus raised plasma ANP level would be associated with atrial overload whereas BNP would be better marker of ventricular overload. ${ }^{20}$

The most recent guideline for the diagnosis and management of CHF drawn by the European Society of Cardiology states that the plasma BNP may be most useful clinically as a rule-out test due to their consistent and very high negative predictive value. ${ }^{21}$

BNP follow the characteristics of an ideal biomarker in the diagnostic and prognostic field of $\mathrm{HF}$ patients. Several studies suggest that BNP exhibits better clinical utility than the other cardiac natriuretic hormones. ${ }^{5,22}$

Yoshimura et al. showed that BNP is secreted predominantly from the ventricles and its plasma levels are markedly increased in patients with HF in relation to its severity. ${ }^{23}$ They also stratified their patients by NYHA classification and showed that BNP concentration progressively increases in relation to the severity of HF. They concluded that measurement of plasma BNP is a simple way of heart failure diagnosis.

Davis et al. showed that plasma BNP level is higher in patients with heart failure compared to patients with lung disease in 52 elderly, who required urgent admission and treatment for acute dyspnea. ${ }^{24}$

\section{Conclusion}

In $\mathrm{HF}$, cardiac congestion generates myocardial stress leading to BNP synthesis from cardiac ventricles. In this study median plasma BNP found to be significantly raised in $\mathrm{HF}$ compared to that in control subjects. So plasma BNP can be studied for its use as a biomarker for diagnosis of HF.

\section{References}

1. Frank J. Congestive heart failure and brain natriuretic peptide. PSA Consult 2002;14: 4-5.

2. Lloyd-Jones DM. The risk of congestive heart failure: Sobering lessons from the Framingham Heart Study. Curr Cardiol Rep 2001; 3:184-190.

3. Boon NA, Fox KAA, Bloomfield P, et al. Cardiovascular disease. In: Haslett, C, Chilvers, ER, Boon, NA, Colledge, NR (eds), Davidson's Principles and practice of medicine, edn. $19^{\text {th }}$ edn, Churchill Livingstone, Edinburgh, 2002, 381-385.
4. Maisel AS, Krishnaswamy P, Nowak RM, et al. Rapid measurement of B-type natriuretic peptide in the emergency diagnosis of heart failure. N Engl J Med 2002;347:161-167.

5. Swedberg K, Cleland J, Dargie H, et al. Guidelines for the diagnosis and treatment of chronic heart failure: executive summary (update 2005). Eur Heart J 2005;26:1115-1140.

6. Stevenson, LW, Perloff, JK. The limited reliability of physical sings for estimating hemodynamics in chronic heart failure. JAMA 1989;261:884-888.

7. Schmitt BP, Kushner MS, et al. The diagnostic usefulness of the history of the patient with dyspnea. J Gen Intern Med 1986;1:386-393.

8. Redfield MM. The breathing not proper trial: enough evidence to change heart failure guidelines? J Card Fail 2002;8:120-123.

9. McCullugh PA, Nowak RM, McCord J, et al. B-type natriuretic peptide and clinical judgment in emergency diagnosis of heart failure. Circulation 2002;106,:416-422.

10. Vinson JM, Rich MW, Sperry JC. Early readmission of elderly patients with congestive heart failure. J Am Geriatr Soc 1990;38:1290-1295.

11. Senni M, Redfield MM. Heart failure with preserved systolic function. J Am Coll Cardiol 2001;38:12771282.

12. Schrier RW, Abraham WT. Hormones and hemodynamics in heart failure. N Engl J Med, vol. 1999;341:577-585.

13. Dao Q, Krishnaswamy P, Kazanegra R, et al. Utility of B-type natriuretic peptide in the diagnosis of congestive heart failure in an urgent-care setting. $\mathrm{J}$ Am Coll Cardiol, 2001;37:379-385.

14. Morrison LK, Harrison A, Krishnaswamy P, et al. Utility of a rapid B-natriuretic peptide assay in differentiating congestive heart failure from lung disease in patients presenting with dyspnea. J Am Coll Cardiol 2002;39:202-209.

15. Axis-Shield Diagnostic 2003, 'Estimation of plasma BNP', In: Operation manual for AxSYM. BNP, Abbott Laboratories, USA.

16. Cowei MR, Sruthers AD, Wood DA, et al. Value of natriuretic peptide in assessment of patients with possible new heart failure in primary care. Lancet 1997;350:1349-1353. 
17. Rahman MS. Role of Plasma BNP (B-type natriuretic peptide) and cTn-I (cardio specific troponin-I) as biomarkers in heart failure (MD Thesis). Dhaka: BSMMU, 2005.

18. Camm AJ. Cardiovascular disease. In: Kumar P, Clark A, eds. Clinical Medicine, $5^{\text {th }}$ ed. Edinburgh: WB Saunders, 2002:754-758.

19. Ruskoah H. Cardiac hormones as diagnostic tools in heart failure. Endocr Rev 2003;24:341-356.

20. Sagnella GA. Measurement and significance of circulating natriuretic peptides in cardiovascular disease. Clin Sci 1998;95:519-529.
21. Remme WJ, Swedberg K. Guidelines for the diagnosis of chronic heart failure. Eur Heart $\mathrm{J}$ 2001;22:1527-1560.

22. Chen HH, Burnett JC. Clinical activation of the natriuretic peptides in heart failure. Eur Heart $\mathrm{J}$ 2006;8:E18-E25.

23. Yoshimura M, Yasue H, Okumura K, et al. Different secretion patterns of natriuretic peptide and brain natriuretic peptide in patients with congestive heart failure. Circulation 1993;87:464-469.

24. Davis M, Espiner E, Richards G, et al. Plasma brain natriuretic peptide in assessment of acute dyspnea. Lancet 1994;343:440-444. 